\title{
Laboreal
}

Volume $5 \mathrm{~N}^{\circ} 1$ | 2009

Ergonomia e desenvolvimento sustentável

\section{Para uma ergonomia construtiva : as condições para um trabalho capacitante}

Hacia una ergonomía constructiva: condiciones para un trabajo capacitante

Pour une ergonomie constructive : les conditions d'un travail capacitant

Promoting constructive ergonomics : the conditions for a capacitating work

\section{Pierre Falzon e Vanina Mollo}

\section{(2) OpenEdition}

Journals

\section{Edição electrónica}

URL: http://journals.openedition.org/laboreal/10429

DOI: 10.4000/laboreal.10429

ISSN: 1646-5237

\section{Editora}

Universidade do Porto

\section{Refêrencia eletrónica}

Pierre Falzon e Vanina Mollo, « Para uma ergonomia construtiva : as condições para um trabalho capacitante », Laboreal [Online], Volume $5 \mathrm{~N}^{0} 1$ | 2009, posto online no dia 01 julho 2009, consultado o 10 outubro 2019. URL : http://journals.openedition.org/laboreal/10429; DOI : 10.4000/laboreal.10429

Este documento foi criado de forma automática no dia 10 outubro 2019.

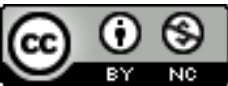

Laboreal está licenciado com uma Licença Creative Commons - Atribuição-NãoComercial 4.0 Internacional. 


\section{Para uma ergonomia construtiva : as condições para um trabalho capacitante}

Hacia una ergonomía constructiva: condiciones para un trabajo capacitante

Pour une ergonomie constructive : les conditions d'un travail capacitant

Promoting constructive ergonomics : the conditions for a capacitating work

Pierre Falzon e Vanina Mollo

\section{NOTA DO EDITOR}

Manuscrito recebido em : Fevereiro/2009

Aceite após peritagem em : Abril/2009

\section{Trabalho e saúde}

\subsection{Ergonomia e medicina construtiva}

1 Em 1957, realizou-se um seminário em Leyden, na Holanda, sob a égide da Agência de Produtividade Europeia. O seu título era "Fitting the job to the worker" (adaptação do trabalho ao homem). 70 Europeus e Americanos participaram no seminário e discutiram a criação de um organismo internacional, que viria a ser mais tarde a International Ergonomics Association. Uma declaração inicial foi redigida por um comité. O seu último parágrafo era o seguinte : 
[...] The changing demands of modern industry, the increasing application of mechanization and automation and the concept of constructive medicine aiming not only at the prevention of disease and accidents, but also at the realization of health all focus attention on man as necessarily the central object of interest in the study of industrial performance.

[...] As novas exigências da indústria moderna, a aplicação crescente da mecanização e da automação bem como o conceito de medicina construtiva visando não apenas a prevenção da doença e dos acidentes mas também a realização da saúde focalizam a atenção sobre o Homem como sendo necessariamente o objecto central de interesse nos estudos da performance industrial (tradução nossa).

2 É mais particularmente o conceito de "medicina construtiva" que será aqui desenvolvido. O que se entende por "medicina construtiva" ? Essa visão construtiva da ergonomia aplica-se unicamente às actividades físicas? Qual é a sua relação com os objectivos gerais da ergonomia ? O que significa ela do ponto de vista dos critérios de avaliação das acções ergonómicas?

3 A saúde pode ser pensada como um estado ou como um processo. Quando ela é pensada como um estado, a saúde é frequentemente definida pela negativa, como a ausência de patologias, de deficiências, de restrições da vida social ou profissional, de miséria económica. Mas a saúde pode ser pensada também como um processo. Nesta perspectiva, ao longo do tempo, as capacidades individuais modificam-se certamente até ao fim da vida, mas :

- esse processo de envelhecimento é sensível às condições de trabalho e de vida. Os operadores que sofrem de más condições de trabalho são mais expostos ao desgaste, aos acidentes e às doenças, e envelhecem por isso de forma diferente ;

- esse processo tem também efeitos positivos. Pela prática, os operadores adquirem experiência, tornam-se competentes, constroem novos saberes e saberes-fazer ;

- entre esses novos conhecimentos, encontram-se as estratégias de adaptação ou de compensação que permitem ao operador experiente proceder de forma diferente e de fazer uso de procedimentos menos exigentes em termos de esforço e mais eficazes. Muitos exemplos desses fenómenos foram descritos em pesquisas ergonómicas sobre o envelhecimento no trabalho (Marquié, Paumès \& Volkoff, 1998).

Existem portanto em ergonomia duas abordagens da saúde complementares. A primeira é correctiva e preventiva. O seu objectivo é o de compensar as deficiências individuais e de evitar as situações geradoras de efeitos negativos. A segunda é construtiva. O objectivo é então o de desenvolver a construção da saúde. Segundo Laville e Volkoff (1993), o propósito é o de "permitir a cada um a construção da sua própria saúde, o seu próprio envelhecimento, da melhor forma possível".

\subsection{A saúde cognitiva}

5 A ergonomia, na sua origem, considerou a saúde sob o ângulo físico. Os aspectos cognitivos foram considerados, mais ou menos implicitamente, como ligados essencialmente ao segundo objectivo da ergonomia : a melhoria da performance e da eficácia. Só recentemente foi tentada uma extensão da saúde ao cognitivo. Maurice de Montmollin (1993) escreveu um dos raros textos publicados sobre esse assunto. Para o autor, a saúde cognitiva "é ser competente, quer dizer, dispor de competências que permitem ser contratado, ter sucesso, progredir. As ignorâncias, os conhecimentos 
aproximados e "em mosaico" podem conduzir a uma "miséria cognitiva", eventualmente fonte de miséria social" (p. 39). Para satisfazer esse objectivo, o ergónomo deve analisar os saberes profissionais, melhorar os programas de formação e definir os instrumentos de assistência apropriados, de forma a manter o par homem/ sistema num equilíbrio não patológico.

o mesmo autor critica em seguida um postulado, subjacente a certos estudos da carga de trabalho, que tende a confundir carga e sobrecarga de trabalho. Segundo essa ideia mais ou menos implícita, toda a carga é negativa. O objectivo do ergónomo deve portanto ser o de eliminar as fontes de dificuldades e de limitar ou eliminar a carga física ou cognitiva. 0 trabalhador ideal é... o trabalhador em repouso.

7 Isto é certamente erróneo. Qualquer actividade engendra uma certa actividade mental (porque não há actividade puramente física) e consequentemente uma certa carga mental. Por outro lado, a carga mental não tem apenas efeitos negativos. Ela pode ter efeitos muito positivos em termos de aprendizagem, de prazer, de satisfação e de realização pessoal. 0 objectivo não é portanto o de suprimir toda a dificuldade, mas de propor dificuldades geríveis e interessantes. 0 que significa isto ?

8 Propor dificuldades geríveis significa, por um lado, dar acesso a recursos sociais cognitivos ou físicos apropriados e, por outro lado, conceber um nível adequado de exigência da tarefa. Uma das fontes do stress é, com efeito, o desequilíbrio entre recursos e exigências : uma tarefa muito exigente e recursos insuficientes. Propor dificuldades interessantes significa definir a tarefa de modo a que permita a mobilização das competências do operador. Trata-se de fazer face às situações exigentes, de resolver os problemas encontrados e, ao fazê-lo, de desenvolver competências. Um trabalho sem desafio não tem outro efeito que o parco interesse para aquele que o realiza. Este último ponto é habitualmente negligenciado. Os seres humanos têm um apetite natural pela construção de novos saberes. Esta é uma observação banal para qualquer ergónomo: os operadores desenvolvem saber-fazer, procedimentos, técnicas no decurso do trabalho e por causa deste. Essa tendência natural para aprender e para descobrir deve ser considerada como um aspecto positivo da actividade humana e ser encorajada o mais possível, já que ela contribui simultaneamente para a qualidade do trabalho para o operador e para o progresso da organização (Falzon, 1996).

9 Na abordagem defendida por Montmollin, a questão fundamental para o ergónomo é : como construir um sistema de trabalho que permita à pessoa uma utilização conseguida do pensamento ? Na abordagem desenvolvimental da saúde cognitiva, a questão seria mais : como conceber um sistema de trabalho que encoraje o desenvolvimento de saberes e competências?

\section{Modelos do desenvolvimento}

O termo desenvolvimento é utilizado por uma variedade de autores e em diversos universos conceptuais. Ele aparece com certeza em psicologia (nomeadamente em psicologia da criança), para enviar em particular para a construção da inteligência ou para os processos de socialização. Este não será o contexto que será aqui privilegiado, apesar de não estabelecermos uma ruptura entre o desenvolvimento da criança e o do adulto. 0 termo desenvolvimento aparece também em trabalhos de enfoque económico. Lembremos de passagem que a ergonomia não saberia satisfazer-se somente com 
modelos de natureza fisiológica, psicológica ou sociológica, por pelo menos duas razões : porque toda a actividade de trabalho se integra num contexto económico e porque a disciplina tem como objectivo a performance dos sistemas sociotécnicos. (cf. A definição da ergonomia: http://www.iea.cc). Esses trabalhos na área da economia podem ser à escala de um país inteiro, como nos trabalhos macroeconómicos sobre os países em desenvolvimento industrial, ou à escala de uma organização de trabalho e dos indivíduos que para ela contribuem. É esta última perspectiva que nos parece pertinente face à perspectiva enunciada na secção precedente. Apresentar-se-ão brevemente dois modelos socioeconómicos do desenvolvimento: a teoria do capital humano e a abordagem pelas "capabilidades".

\subsection{Capital humano e organização aprendente}

11 A teoria do capital humano foi proposta por Gary Becker (Prémio Nobel de economia 1992) numa obra publicada em 1964. Para Becker, cada indivíduo dispõe de um stock de saberes, experiências, saberes-fazer, que constituem um capital que é seu, que ele pode (ou não) desenvolver. Do ponto de vista da organização, esse capital humano pode em certa medida ser comparado aos meios físicos de produção. Em particular, é possível investir no capital humano (pela educação, a formação profissional, a saúde) e obter retornos positivos desse investimento.

Há no entanto diferenças entre o capital humano e as outras formas de capital. Por um lado, apesar de poder ser substituído (pela contratação de outros indivíduos), ele não é transferível como uma propriedade física pode ser. Por outro lado, ele apresenta características particulares, ligadas à natureza do saber. Com efeito, o saber é :

- extensível e auto-gerado no decurso do seu uso : a aquisição da experiência de um operador traduz-se pelo crescimento daquilo que sabe, e portanto da sua dotação de capital humano. A economia da raridade é substituída por uma economia da auto-geração ;

- nómada e partilhável (com outros), sem que essa transferência se traduza por uma perda para o detentor original (no entanto, essa transferência pode diminuir a raridade desse saber e logo o seu valor mercantil para o detentor inicial).

O conceito de organização aprendente (Argyris \& Schön, 1978) inscreve-se nesse quadro. Para os seus promotores, uma organização aprendente visa desenvolver de forma constante o seu capital humano, tirando partido de projectos que ela desenvolve, das dificuldades que ela encontra, dos seus sucessos, das suas interacções com os seus parceiros, partilhando os conhecimentos.

Segundo Senge (1991), as organizações aprendentes são "aquelas cujos membros podem desenvolver sem cessar as suas capacidades para atingir os resultados que procuram, onde novos modos de pensamento são aperfeiçoados, onde as aspirações colectivas não são travadas, onde as pessoas aprendem permanentemente como aprender juntas".

\subsection{Capacidades e desenvolvimento humano}

Amartya Sen (Prémio Nobel da economia 1998) questionou “a visão puramente económica do desenvolvimento, unicamente percebido em termos de aumento do PIB ou do rendimento real, em benefício de uma visão mais larga do desenvolvimento que integra as oportunidades e o espaço de liberdade de um indivíduo para levar a vida 
escolhida" (Bryson \& Merritt, 2007, p. 42). A sua teoria da escolha social parece muito útil para fundar os objectivos e os métodos da ergonomia.

Um aspecto fundamental do modelo de Sen (1999) é a ideia de "capabilidade". Esta é definida como o conjunto dos funcionamentos humanos disponíveis a um indivíduo, quer deles faça uso ou não. Para Sen, as possibilidades realmente disponíveis a uma pessoa não podem ser concebidas somente em termos de acesso a bens primários ou em termos de direitos formais. Consideremos por exemplo o direito de voto. Para Sem (1999), este conceito é vazio de sentido. Ele perguntaria mais se as condições que transformam o direito de voto em "capabilidade" de votar estão reunidas. Uma "capabilidade" de votar requer muitos elementos : um nível suficiente de educação, um acesso real e equitativo à informação política, uma organização eficaz dos processos eleitorais. Consequentemente, num dado país, pode haver um direito formal de voto para todos e uma "capabilidade" real de votar muito desigual segundo os indivíduos. 0 objectivo dos poderes públicos deve ser o de tornar as pessoas iguais em termos de "capabilidades", não somente em termos de direitos formais ou de recursos económicos.

Segundo este modelo, o que importa portanto, são as "capabilidades" reais de cada indivíduo, que permitem uma real liberdade de escolha em todos os momentos da vida, garantindo assim a possibilidade de desenvolvimento pessoal. $\mathrm{O}$ bem-estar e a liberdade não resultam da existência de diferentes opções, mas da possibilidade real de escolher entre essas opções. Alguns autores utilizam indiferenciadamente capacidade e "capabilidade" para dar conta do conceito proposto por Sen. Essa amálgama deve ser evitada, em particular em ergonomia. A capacidade remete para o facto de se saber fazer qualquer coisa. A "capabilidade" remete para o facto de se estar em condições de fazer qualquer coisa, o que significa que se tem a capacidade, mas também a possibilidade real. A ideia de actividade impedida (Clot, 1999) pode ser vista sob este ângulo : uma capacidade sem "capabilidade".

Esta abordagem apresenta um parentesco com o conceito de poder de agir. 0 poder de agir é a possibilidade efectiva de mobilizar uma dada capacidade. $O$ poder de agir tem assim uma ligação com a relação entre um sujeito e o seu ambiente, já que a mobilização de uma capacidade não depende apenas da disponibilidade dessa capacidade, mas também de um conjunto de condições organizacionais, técnicas, sociais, etc. (Zimmerman, 1995).

\subsection{Para um desenvolvimento conjunto das pessoas e das organizações : o ponto de vista da ergonomia}

O parentesco destes dois modelos com a ergonomia é claro. A ergonomia não pode senão subscrever a ideia de Becker segundo a qual saberes e saberes-fazer se constroem no próprio exercício da actividade de trabalho. Não pode igualmente deixar de subscrever a ideia de Sen segundo a qual as "capabilidades" de um indivíduo supõem um ambiente favorável para que elas possam ser exercidas. A partir do momento em que Sen descreve as condições necessárias para que um direito formal se torne uma "capabilidade" real, ele descreve um contexto, logo um ambiente. Existem no entanto diferenças entre os modelos de Sen e de Becker. Segundo Sen (1997), o capital humano remete para a "capacidade dos indivíduos - através das suas competências, dos seus conhecimentos e dos seus esforços - para aumentarem as possibilidades de produção", 
enquanto que a "capabilidade" se define como "a capacidade dos indivíduos para levar a vida que têm razões de valorizar".

Este ponto é sublinhado por Bryson e Merritt (2007, p.44), para quem "o capital humano é frequentemente percebido em termos de contribuição para a produtividade da organização, enquanto que a "capabilidade" é considerada como uma contribuição mais ampla permitindo aos indivíduos melhorarem a sua vida em geral" Sen focaliza-se sobre os objectivos humanos. É nesse sentido uma teoria da liberdade, para além de um modelo económico. Se lermos bem essa diferenciação, notamos que aí encontramos os objectivos da ergonomia : aqueles ligados às organizações e aqueles ligados às pessoas. A questão é assim sempre a mesma. No mundo real, a ergonomia deve perseguir conjuntamente os dois objectivos. A recente obra de Zink (2008) sobre a sustentabilidade é um exemplo de uma tal tentativa de articulação, assim como os escritos sobre os benefícios económicos das intervenções ergonómicas (Oxenburgh, Marlow \& Oxenburgh, 2004).

o desafio para o ergónomo é então o de desenvolver o potencial capacitante das organizações de modo a que elas contribuam simultaneamente e de forma perene para a melhoria do bemestar dos assalariados, para o desenvolvimento das competências e para a melhoria da performance. Toda a organização dispõe de um potencial capacitante mais ou menos importante. Mas esse potencial é muitas vezes subexplorado, desconhecido ou não reconhecido, talvez mesmo entravado pela organização. $O$ desafio é então não tanto o de criar uma nova tarefa "capacitante" que se viria acrescentar às tarefas existentes, mas o de organizar o existente de forma a que permita aos indivíduos e às organizações progredir.

Através de uma análise da actividade das reuniões pluridisciplinares de concertação (RPC) em oncologia, a secção seguinte mostra que essas RPC constituem um recurso importante para o desenvolvimento de saberes colectivos partilhados e para a produção de decisões fiáveis.

\section{As Reuniões Pluridisciplinares de Concertação em oncologia : um tipo particular de ambiente capacitante}

Em oncologia, os médicos dispõem de duas ferramentas de apoio à decisão :

- os referenciais terapêuticos, que consistem num conjunto de regras derivadas da medicina sustentadas em provas. Estas regras resultam da compilação de resultados de ensaios terapêuticos efectuados em populações homogéneas de pacientes.

- as Reuniões Pluridisciplinares de Concertação (RPC), que reúnem diferentes especialistas (cirurgiões, radioterapeutas, médicos oncologistas, etc.) para tratar das situações que não podem ser tratadas através da aplicação directa dos referenciais.

O estudo aqui apresentado foi realizado num Centro de luta contra o cancro especializado no tratamento do cancro da mama, e visava compreender o papel do debate colectivo realizado nas RPC sobre o desenvolvimento de saberes, tanto ao nível individual como ao nível colectivo. Vamos mostrar como o raciocínio colectivo realizado em cada caso apresentado nas RPC permite não só responder aos objectivos funcionais (encontrar uma solução), mas também, ao mesmo tempo, desenvolver o conhecimento. Na verdade, a procura de soluções para um caso particular implica uma reflexão sobre as próprias regras, e, portanto, a construção de regras colectivas locais. 
As RPC são lugares de intercâmbio e de desconstrução de saber : a apresentação dos casos encoraja os profissionais a declarar, espontaneamente ou em resposta a questões dos colegas, as regras da sua arte (por exemplo, para justificar a sua recusa de determinada acção terapêutica). Além disso, o raciocínio colectivo realizado em cada caso constitui de facto uma reflexão sobre os referenciais. Trata-se de decidir sobre a aplicabilidade dessas regras, ou seja de definir o seu campo de validade, e de definir eventualmente as adaptações das aç̧ões necessárias. Ao fazê-lo, os saberes são partilhados e construídos, a actividade de tomada de decisão contribuindo para o desenvolvimento dos saberes colectivos compartilhados.

\subsection{Metodologia}

O estudo dos efeitos da RPC sobre o desenvolviento dos saberes individuais e colectivos partilhados não podia limitar-se à análise da actividade realizada nas RPC, por duas razões essenciais :

- o próprio funcionamento das RPC faz com que a explicitação dos raciocínios e dos saberes subjacentes, não seja suficiente na óptica de um estudo sistemático, já que os intercâmbios entre médicos comportam uma parte implícita demasiado grande ;

- a análise das RPC não permite colocar em evidência os efeitos do debate colectivo no desenvolvimento de saberes: os efeitos induzidos nos indivíduos e no colectivo não são directamente acessíveis através da simples observação.

O estudo consistiu, portanto, em simular a actividade das RPC, de maneira a analisar in vitro o que se produz in vivo nas reuniões. Para o fazer, foi colocada em prática uma metodologia de explicitação de saberes (detalhada em Mollo \& Falzon, 2008). Foi realizada em duas fases.

Num primeiro momento, 19 médicos (6 radioterapêutas, 6 cirurgiões, 6 oncologistas, 1 ginecologista) foram convidados a resolver em voz alta 14 problemas experimentais implicando elementos perturbadores, ou seja, factores que tornam impossível a aplicação directa do referencial. Estes problemas foram construídos com um especialista do centro, e diziam respeito não ao diagnóstico, mas à escolha de tratamentos.

O exemplo abaixo descreve um tipo de problema apresentado (P1 daqui em diante) :

Paciente de 54 anos, já na menopausa, tratada através de cirurgia conservadora a um tumor no quadrante superior-externo do seio direito. A análise histológica descreveu um carcinoma ductal invasor de $28 \mathrm{~mm}$ de grau II, os gânglios axilares estão invadidos de células cancerosas, e o tumor é sensível às hormonas. A paciente apresentou uma embolia pulmonar há um mês.

De acordo com o referencial, a paciente deveria ser submetida a uma radioterapia, a uma quimioterapia e a uma terapia hormonal de Tamoxifeno (nome da medicação). 0 elemento perturbador é a embolia pulmonar, que contra-indica o Tamoxifeno.

31 Numa segunda fase, uma sére de allo-confrontações individuais foi realizada com 13 dos 19 médicos, vistas individualmente. Trata-se de uma forma de verbalização consecutiva assistida pelos traços da actividade, neste caso concreto, traços áudio, que consiste em confrontar um sujeito com a actividade de um ou vários colegas, na ausência destes (Mollo \& Falzon, 2003, 2004) : os médicos devem comentar as soluções propostas pelos colegas, que diferem das que eles próprios propuseram. Não era possível abordar os 14 
problemas na medida em que esta experimentação exigia mais tempo do que a primeira, e porque a duração das entrevistas não podia exceder uma hora. 6 problemas foram então seleccionados com base na diversidade observada ao nível das soluções propostas na primeira fase, bem como no grau de divergência entre as diferentes soluções (as soluções para um mesmo problema podem variar entre a adaptação de um tratamento e a sua supressão).

Um total de 27 soluções foram avaliadas. Estas soluções foram completadas por extractos de verbalizações de maneira a que os médicos tivessem acesso à justificação da escolha dos seus colegas. Os extractos abaixo ilustram os extractos de verbalização seleccionados para o problema P1 descrito acima :

D1 : "A terapia hormonal vai começar daqui a uns meses; a paciente recebeu um tratamento anticoagulante devido à sua embolia, podemos por isso precrever-lhe o Tamoxifeno sem problemas »

D2: "Tendo em conta o seu histórico de embolia pulmonar, inclinar-me-ia para não lhe dar terapia hormonal, porque, mesmo sendo tratada com anticoagulante, temo que ela volte a ter uma embolia pulmonar"

No final de cada problema, os médicos eram livres de validar ou de modificar as suas escolhas iniciais, a fim de analisar mudanças eventuais das soluções.

\subsection{As RPC como ferramentas de desenvolvimento de saberes partilhados}

Nas allo-confrontações individuais, os médicos avaliaram o grau de aceitabilidade daquelas soluções propostas pelos seus colegas, que não tinham sido por si consideradas ou que, tendo sido por si consideradas, tinham acabado por rejeitar. A análise destas avaliações consistiu em classificar as soluções avaliadas como aceitáveis ou inadequadas em função do grau de consenso entre os diferentes médicos. Este grau de consenso corresponde ao grau de concordância entre os médicos sobre a avaliação das diferentes soluções.

o quadro 1 representa o grau de consenso entre os médicos, segundo o facto de estes últimos terem considerado a solução avaliada como aceitável ou inadequada.

Os resultados mostram que as RPC permitem tornar os limites dos referenciais mais flexíveis e, ao mesmo tempo, delimitam o campo das adaptações possíveis, além do qual as práticas são consideradas inaceitáveis em termos de segurança dos pacientes. 
Quadro 1. Distribuicao de solucoes julgadas aceitaveis ou inadequadas em funcao do grau de consenso (C) entre os medicos (exemplo de leitura da primeira celula do quadro : 5 das 27 solucoes sao consideradas aceitaveis por todos os medicos que as avaliaram, mesmo que nao fizessem parte das suas opcoes iniciais).

\begin{tabular}{|c|c|c|c|c|c|c|}
\hline & $C=100 \%$ & $100 \%, C \geq 75 \%$ & $75 \%>C \geq 60 \%$ & $60 \%>C>50 \%$ & $C=50 \%$ & \\
\hline $\begin{array}{l}\text { Soluções } \\
\text { aplicáveis }\end{array}$ & 5 & 3 & 4 & 0 & \multirow{2}{*}{2} & \\
\hline $\begin{array}{c}\text { Soluçōes } \\
\text { inadequadas }\end{array}$ & 6 & 4 & 2 & 1 & & \\
\hline$\Sigma$ & 11 & 7 & 6 & 1 & 2 & 27 \\
\hline \multicolumn{7}{|c|}{$\begin{array}{l}\text { Quadro 1. Distribuição de soluções julgadas aceitáveis ou inadequadas em função do grau de } \\
\text { consenso (C) entre os médicos (exemplo de leitura da primeira célula do quadro: } 5 \text { das } 27 \text { soluçōes } \\
\text { são consideradas aceitáveis por todos os médicos que as avaliaram, mesmo que não fizessem parte } \\
\text { das suas opçōes iniciais). }\end{array}$} \\
\hline
\end{tabular}

378 das 27 soluções são consideradas aceitáveis por, pelo menos, $75 \%$ dos médicos que as avaliaram, embora não façam parte das suas opções iniciais. Por exemplo, um problema descrevia uma paciente que apresentava um tumor de $5 \mathrm{~cm}$ e que recusava a ablação do seio recomendada pelo referencial. Sendo o volume dos seios desta paciente importante, era possível considerar uma cirurgia conservadora. Uma solução proposta na primeira experimentação consistia em começar o tratamento com quimioterapia na esperança de que o tumor regredisse e, em seguida, realizar uma cirurgia conservadora se a quimioterapia tivesse sido efectivamente eficaz. Os 6 médicos que avaliaram esta solução consideraram-na aceitável, ainda que inicialmente tivessem proposto a ablação do seio.

38 Estes resultados mostram que a decisão colectiva permite estender o campo de adaptabilidade das regras terapêuticas. Na verdade, quando um problema vai para além do quadro do referencial terapêutico, não existe uma mas várias soluções fiáveis aceitáveis, e essa diversidade é reconhecida e aceite pelo colectivo.

39 Em contrapartida, 10 das 27 soluções são julgadas como inadequadas por pelo menos $75 \%$ dos médicos que as avaliaram. Olhando para o problema P1 descrito anteriormente, os 7 médicos que tinham avaliado a solução "Tamoxifeno ", consideraram-na inaceitável porque comporta um risco para o paciente, já que existem soluções menos eficazes mas muito menos arriscadas do que o Tamoxifeno.

40 As RPC desempenham, assim, um papel de protecção, eliminando soluções terapêuticas inaceitáveis. Mas, ao fazê-lo, fornecem igualmente aos médicos um quadro de referência, dentro do qual eles são livres de aplicar as suas próprias regras, sendo asseguradas a fiabilidade e a aceitabilidade colectiva das suas decisões. $\mathrm{Na}$ verdade, graças aos intercâmbios realizados nas RPC, os médicos integram novos saberes que não teriam em conta se tivessem raciocinado individualmente.

41 A secção seguinte tem como objectivo avaliar os efeitos da confrontação colectiva sobre a actividade individual de tomada de decisão. 


\subsection{A evolução das decisões individuais}

42 Como mencionado anteriormente, no final de cada problema comentado, os médicos eram livres de validar ou modificar as escolhas que tinham efectuado durante a primeira fase de recolha de dados.

43 A comparação entre as soluções propostas no decurso da resolução dos problemas experimentais e as soluções propostas após as allo-confrontações individuais mostra que em $48 \%$ dos casos, os médicos modificam as suas escolhas iniciais.

Este resultado é importante em termos de impacto terapêutico, Com efeito, a primeira fase de recolha de dados mostra que segundo o médico que os teria atendido, os pacientes não teriam recebido o mesmo tratamento. Quanto à segunda fase de recolha, ela mostra que os pacientes podem receber um tratamento diferente em função de o médico ter ou não submetido a sua decisão ao colectivo.

Três grandes tipos de alterações puderam ser observadas e em função de elas consistirem em aperfeiçoar a escolha inicial, ampliá-la ou substitui-la.

\subsubsection{0 aperfeiçoamento da escolha inicial}

Este tipo de alteração refere-se a situações nas quais os médicos conservam as soluções que propuseram na primeira experimentação, mas hierarquizam-nas $(9,52 \%)$, ou invertem a hierarquia inicial (1,19\%).

47 A análise das relações entre este tipo de alterações e a incerteza dos médicos face à decisão leva a concluir que a allo-confrontação desempenhou um papel de ajuda na decisão : a leitura de excertos de verbalizações dos seus colegas permitiu aos médicos aceder a dados que lhes faltavam para tomar a sua decisão e integrá-los no seu raciocínio (desenvolvimento da base individual de saberes).

\subsubsection{A ampliação da escolha inicial}

Em contraste com o ponto anterior, a confrontação com soluções de colegas conduziu certos médicos a alargar as suas escolhas iniciais, quer através da eliminação da hierarquização inicialmente estabelecida (2,38\%), quer acrescentando à sua solução inicial de primeira intenção uma solução proposta pelos seus colegas $(8,33 \%)$, ou através da integração de uma solução proposta pelos seus colegas, mas em segundo lugar nas suas intenções, privilegiando assim a sua própria escolha (16,67 \%).

Em ambos os casos anteriores, os médicos integram novas opções terapêuticas que julgam equivalentes (no plano terapêutico) às suas.

\subsubsection{A substituição da escolha inicial}

Em certas situações, os médicos substituíram uma (1,19\%) ou mais frequentemente a totalidade $(8,33 \%)$ das soluções consideradas. Este tipo de alteração, embora rara, é importante, na medida em que os médicos substituem as suas soluções iniciais por novas soluções que eles julgam mais bem adaptadas.

51 Todos estes elementos confirmam o facto de que não existe uma mas várias regras de adaptação lícitas para um mesmo problema. Mostra igualmente que o debate realizado nas RPC permite o desenvolvimento de saberes colectivos partilhados mas também 
individuais, na medida em que desempenha um papel importante na difusão de saberes de referência locais (por oposição aos do referencial), e na decisão individual.

\subsection{Conclusão do estudo}

Os resultados deste estudo mostram que as RPC participam conjuntamente na performance da organização, através da produção de decisões fiáveis, e no desenvolvimento de saberes individuais e colectivos. Assim, embora o estudo seja baseado numa metodologia semi-experimental, não é posto em causa o carácter transponível dos resultados obtidos. Por um lado, os resultados complementam e vão de encontro aos de Sauvagnac (2000) obtidos a partir da observação das RPC. Por outro lado, a allo-confrontação individual parecia familiar aos médicos, em particular porque eles estão habituados a este género de exercício nas RPC. Isto facilitou a compreensão das instruções, e assim a recolha de dados. Finalmente, os dados obtidos foram validados pelos actores no terreno. No entanto, fenómenos sociais específicos das situações reais (por exemplo os fenómenos de influência relacionados com as posições hierárquicas dos actores) são dificilmente reproduzíveis num estudo semiexperimental. Nós pensamos, todavia, que isso não invalida os resultados obtidos.

o debate colectivo consiste mais em definir o espaço das soluções possíveis e impossíveis do que de avançar para uma solução única aceitável (embora possa ser necessária em certas situações). Assim, as RPC fornecem um quadro de referência fiável, no qual os médicos são livres de escolher, de entre as possíveis regras, aquelas que lhes parecem corresponder melhor às situações particulares, e à sua própria mestria. Ao fazêlo, as RPC participam igualmente no desenvolvimento dos saberes individuais, já que os médicos são conduzidos a integrar as regras construídas no decurso da confrontação. Trata-se, portanto, de um ambiente capacitante. No curso de uma decisão colectiva, partilham-se saberes, adaptam-se, criam-se novos. o desafio é então o de permitir aos saberes solicitados no dia-adia para tomar decisões sejam reconhecidos e utilizados como premissas do desenvolvimento de novos saberes partilhados. Mas como ? E em que condições?

Uma primeira condição consiste em traçar as decisões tendo em vista uma eventual reutilização posterior. Isto significa uma formulação explícita da questão levantada pelo dossier do paciente e da resposta surgida na RPC, com as suas justificações. Uma revisão sistemática e periódica das decisões tomadas e armazenadas permitiria então nas RPC identificar as práticas regulares que emergem, potencialmente geradoras de novidade: é o caminho de uma integração com êxito dos resultados da prática especializada local nos referenciais provenientes da medicina sustentada em provas.

No entanto, para que participe eficazmente no progresso dos conhecimentos, esta actividade reflexiva colectiva necessita de tempo. Esta segunda condição parece comprometida, não só pela frequência de RPC nas quais os médicos participam voluntariamente, mas também pelo facto de a actividade de primeira tomada de decisão para os pacientes particulares não dever ser prejudicada pela implementação de uma actividade reflexiva. Um tal funcionamento seria arriscado, já que a prioridade é para o desenvolvimento de decisões fiáveis para os casos em que não existe resultado provado cientificamente.

Por último, a actividade reflexiva deve ser conhecida por todos e reconhecida, encorajada e assistida. Infelizmente, este objectivo parece comprometido pelas 
prescrições recentes dos sistemas de saúde que impõem que se trate em RPC todos os casos de pacientes, ou seja tanto os casos "protocolares" (para os quais a aplicação de referenciais terapêuticos é suficiente) como os casos particulares, actualmente apresentados em RPC. Este modo de funcionamento destrói o potencial capacitante das RPC, e é contraproducente por várias razões. Por um lado, compromete a implementação, já limitada actualmente, de uma actividade reflexiva colectiva, e consequentemente, compromete o desenvolvimento dos saberes individuais $\mathrm{e}$ colectivos. Por outro lado, vai contra os objectivos de performance : o tratamento de casos protocolares reduz o tempo atribuido ao tratamento de casos não protocolares, $o$ que aumenta o risco de erros e consequentemente reduz a fiabilidade das decisões. Finalmente, mobiliza competências raras, especializadas, para decisões simples, competências essas competências que poderiam participar no progresso do conhecimento médico. Estamos a assistir, portanto, a um verdadeiro "desperdício" cognitivo (Mollo \& Sauvagnac, 2006).

\section{Por uma ergonomia construtiva}

O exemplo referido anteriormente evidencia a possibilidade de uma articulação entre a prossecução de objectivos imediatos (a tomada de decisão sobre um caso) e a longo prazo (construção colectiva de regras de decisão fiáveis). Esta articulação só é possível se certas regras de funcionamento organizacional forem respeitadas, definindo assim um ambiente capacitante, conforme esboçado acima. Esta secção procura clarificar a noção de ambiente capacitante.

\subsection{Obstáculos e condições de um trabalho capacitante}

Toda a actividade de trabalho implica uma actividade funcional orientada para a realização da tarefa, e uma actividade meta funcional, ou reflexiva, que tem por objecto a própria actividade e que visa transformá-la (Falzon, 1994). A actividade reflexiva não está directamente orientada para a produção imediata; ela permite a construção de saberes ou de ferramentas (ferramentas materiais ou ferramentas cognitivas) destinadas a uma eventual utilização posterior, e visa facilitar a execução da tarefa ou melhorar a performance (Falzon \& Teiger, 1995 ; Falzon, Sauvagnac \& Chatigny, 1996). Mas ela tem lugar à margem do trabalho (ela insere-se no tempo de trabalho, em paralelo com a actividade funcional ou durante fases de menor actividade), e encontra a sua origem no trabalho.

O desafio é então que esta actividade particular de elaboração e de descoberta dos saberes elaborados durante a resolução do problema seja reconhecida como uma actividade necessária para a organização. Para isso, é necessário que a organização tome consciência do seu potencial capacitante, isto é, do facto de que uma utilização manifesta e reflexiva dos seus próprios recursos constitui por si só um caminho prometedor para a melhoria contínua do desempenho.

Tal postura parece contraditória com o aumento da prescrição de procedimentos que se verifica em muitas situações de trabalho. Na verdade, a pressão temporal da produção é tal que os operadores não têm tempo para se dedicar a este trabalho de abstracção. Esta redução das margens de manobra resulta de um desconhecimento e de uma incompreensão do papel das actividades reflexivas, e do papel que os operadores 
podem desempenhar. Na verdade, as políticas de melhoria (da segurança, da qualidade, da produtividade, etc.) baseadas essencialmente no desenvolvimento de diversas ferramentas (procedimentos, tecnologias, etc.), esquecem o importante papel dos Homens. Como sublinha Daniellou (2008), estas lógicas de gestão impedem a expressão real dos trabalhadores. Portanto, o conhecimento que estes últimos têm da situação na qual trabalham assim como a sua capacidade adaptativa constituem um valor seguro que é essencial conservar e assistir em prol de uma melhoria contínua. A actividade reflexiva pode assim ser considerada como participante numa demarche de prevenção : o desenvolvimento e a formalização de saberes permite antecipar melhor situações futuras e evitar o aparecimento de certas situações problemáticas.

61 Do ponto de vista metodológico, tal perspectiva exige que se ponha em evidência a existência de actividades reflexivas e os seus benefícios. Isto requer um alargamento do olhar do ergónomo para colocar em evidência, explorar e valorizar as actividades reflexivas, em vez de se centrar sobre a performance imediata. Com efeito, os operadores só se interessarão por esta tarefa de formalização de saberes se ela se apresentar como directamente relevante para o cumprimento da tarefa, a partir do seu ponto de vista, e não como "mais" uma tarefa, com objectivos pouco claros (Falzon \& Teiger, 1995).

Do ponto de vista da postura do ergónomo, trata-se de pôr em prática uma situação dinâmica de desenvolvimento, de integrar as estratégias das organizações, a fim de permitir um desenvolvimento contínuo e sustentável dos saberes. É este ponto de vista que nós qualificamos de ergonomia construtiva.

\subsection{Características de um ambiente capacitante}

Os efeitos das intervenções ergonómicas podem ser pensados em termos do desenvolvimento do poder de agir das pessoas e da implementação de ferramentas que permitam progredir. A aquisição de competências é uma forma de desenvolvimento das "capabilidades" uma vez que aumenta o número de opções às quais os operadores têm acesso. Do mesmo modo, permitir aos operadores margens de manobra sobre os objectivos da tarefa ou sobre os critérios a satisfazer aumenta as "capabilidades", uma vez que as opções possíveis aumentam. Por último, permitir às equipas que definam a sua própria actividade colectiva aumenta a sua "capabilidade".

Portanto, a questão que se coloca do ponto de vista da ergonomia é a das características de um ambiente capacitante. Proporemos aqui uma definição a partir de três pontos de vista : preventivo, universal e desenvolvimental. Estes pontos de vista contribuem para o desempenho global do sistema e definem um trabalho sustentável.

De um ponto de vista preventivo, um ambiente capacitante é um ambiente que não produz efeitos nefastos sobre o indivíduo e preserva assim a sua futura capacidade de agir. Trata-se, evidentemente, de um aspecto muito clássico das intervenções ergonómicas : detectar e prevenir os riscos, eliminar a exposição aos tóxicos, eliminar a exposição à exigência de tarefas que levam, a longo prazo, a deficiências ou a efeitos psicológicos negativos, etc. Mas isto também se refere à preservação das capacidades físicas bem como à salvaguarda da competências das pessoas.

De um ponto de vista universal, um ambiente capacitante é um ambiente que têm em conta as diferenças inter-individuais (em termos de características antropométricas, mas também em termos de idade, de género, de cultura) e que compensa as deficiências 
individuais (ligadas ao envelhecimento, às doenças, às incapacidades). É, portanto, um ambiente que prevê a exclusão e o desemprego.

De um ponto de vista desenvolvimental, um ambiente capacitante é um ambiente que permite às pessoas que desenvolvam novos saberes e saberes-fazer, que alarguem as suas possibilidades de acção, o seu grau de controlo sobre as suas tarefas e sobre a forma como eles as realizam, isto é, a sua autonomia. Um ambiente capacitante contribui para o desenvolvimento cognitivo das pessoas e das equipas e, consequentemente, encoraja a aprendizagem.

\section{Conclusão}

Foram apresentadas até agora as semelhanças entre a abordagem pelas "capabilidades" e a abordagem ergonómica. Insistiremos nesta conclusão sobre as proximidades destas abordagens com a noção de desenvolvimento sustentável. Este último é definido como "um desenvolvimento que responde às necessidades das gerações do presente sem comprometer a capacidade das gerações futuras de responderem às suas" (United Nations, 1987). Subjacente a esta definição encontra-se a ideia de preservação de recursos, nomeadamente energéticos. Esses são pensados como finitos, não renováveis (pelo menos a muito longo prazo), daí o interesse por energias alternativas (solar, eólica), que são inesgotáveis. Na mesma perspectiva, um ambiente capacitante visa evitar os efeitos nocivos, preservar as capacidades de agir, de modo a não comprometer o futuro. Mas é o ponto de vista desenvolvimental aquele que sublinharemos aqui. o postulado de base da ergonomia construtiva é, com efeito, o desenvolvimento contínuo dos recursos. Contrariamente aos recursos materiais, os saberes e os saberes-fazer dos indivíduos não irão esgotar-se (no sentido em que eles iriam diminuindo). Eles podem tornar-se obsoletos se não se mantiverem em dia, mas também podem ser transformados, refinados, desenvolvidos, de um modo constante e infinito.

O desenvolvimento dos saberes e dos saberes-fazer tem assim um duplo estatuto. É por um lado uma condição de progresso individual, de manutenção do emprego (através da actualização e melhoria das competências) e de satisfação no trabalho. É por outro lado uma condição de progresso das organizações. $O$ desafio de hoje é que esta dimensão de desenvolvimento do trabalho seja reconhecida como uma actividade necessária à organização e às pessoas (Falzon \& Teiger 1995 ; Falzon, Sauvagnac \& Chatigny, 1996).

\section{BIBLIOGRAFIA}

Argyris, C. \& Schön, D. (1978) Organizational Learning : A theory of action perspective. AddisonWesley, Reading MA, 1978.

Becker, G.S. (1964). Human Capital : A Theoretical and Empirical Analysis, with Special Reference to Education. Chicago, University of Chicago Press. 
Bryson, J. \& Merritt, K. (2007). Le travail et le développement des capacités. Formation-Emploi, 98, 41-54.

Clot, Y. (1999). La fonction psychologique du travail. Paris : PUF.

Daniellou, F. (2008). Développement des TMS : désordre dans les organisations et fictions managériales. 2ème congrès francophone sur les troubles musculo-squelettiques : de la recherche à l'action. Montréal, 18-19 juin 2008.

Falzon, P. (1994). Les activités méta-fonctionnelles et leur assistance. Le Travail Humain, 57, 1, 1-23.

Falzon, P. (1996). Des objectifs de l'ergonomie. In F. Daniellou (Dir). L'ergonomie en quête de ses principes (pp. 233-242). Toulouse : Octarès.

Falzon, P. \& Teiger, C. (1995). Construire l'activité. Performances Humaines \& Techniques, Hors Série (septembre), 34-39.

Falzon, P., Sauvagnac, C., \& Chatigny, C. (1996). Collective knowledge elaboration. In COOP Group (Ed.), Second International Conference on the Design Cooperative Systems (pp. 171-186). Juan les Pins : INRIA.

Laville, A. \& Volkoff, S. (1993). Age, santé, travail : le déclin et la construction. Actes du XXVIIIème congrès de la SELF, Genève, 2224 septembre 1993.

Marquié, J.C., Paumès, \& Volkoff, S. (1998). Working with age. London : Taylor \& Francis.

Mollo, V. \& Falzon, P. (2003). Formalizing confrontation methods : a categorization attempt. XVth Triennial Congress of the International Ergonomics Association, "Ergonomics in the Digital Age", August 24-29, 2003, Seoul, Korea.

Mollo, V. \& Falzon, P. (2004). Autoand allo-confrontation as tools for reflective activities. Applied Ergonomics, 35, 6, 531-540.

Mollo, V. \& Falzon, P. (2008). The development of collective reliability : a study of therapeutic decision-making. Theoretical Issues in Ergonomics Science, 9, 3, 223-254.

Mollo, V. \& Sauvagnac, C. (2006). La décision médicale collective. Pour des médecins moins savants et moins autonomes? Paris : L'Harmattan.

Montmollin, M. de (1993). Compétences, charge mentale, stress : peuton parler de santé "cognitive" ? Actes du XXVIIIème congrès de la SELF, Genève, 22-24 septembre 1993.

Oxenburgh, M., Marlow, P. \& Oxenburgh, A. (2004). Increasing productivity and profit through health and safety ; the financial returns from a safe working environment (2nd ed.). Boca Raton, Florida : CRC Press.

Sauvagnac, C. (2000). Laconstructiondeconnaissancesparl'utilisation et la conception de procédures. Contribution au cadre théorique des activités métafonctionnelles. Thèse de doctorat en Ergonomie, CNAM, Paris.

Sen, A. (1997) Editorial : Human capital and human capability. World Development, 34, 3.

Sen, A. (1999). Development as freedom. Oxford : Oxford University Press. Senge, P. (1991). La cinquième discipline. Paris : Editions First.

United Nations. (1987). Report of the World Commission on Environment and Development. General Assembly Resolution 42/187, 11 December 1987.

Zimmerman, M.A. (1995). Psychological empowerment : issues and illustrations. American Journal of Community Psychology, 23, 5, 581-599. 
Zink, K.J. (2008). Corporatesustainabilityasa Challengeforcomprehensive management. Berlin : Springer.

\section{RESUMOS}

O artigo apresenta os objectivos de uma ergonomia construtiva, visando não apenas a eficácia do trabalho mas também o desenvolvimento constante e conjunto dos operadores e das organizações. Esta abordagem articula os modelos socioeconómicos propostos por G. Becker e A. Sen. Ela é ilustrada por um estudo do trabalho de um colectivo de médicos especializados em oncologia que têm que escolher uma terapêutica para casos complexos. Mostra-se que, paralelamente à tomada de decisão em relação a cada caso, eles desenvolvem uma reflexão sobre as boas práticas, favorecendo, por um lado, o desenvolvimento dos saberes de cada um e do colectivo e, por outro lado, a fiabilidade global das decisões. A conclusão introduz a noção de ambiente capacitante, cujas características são esboçadas.

ambiente capacitante, ergonomia construtiva, actividade reflexiva, desenvolvimento de saberes

Este artículo presenta los objetivos de una ergonomía constructiva apuntando no solamente a la eficacia del trabajo sino, también, al desarrollo constante y conjunto de los operadores y de la organización. Este enfoque articula los modelos socioeconómicos propuestos por G. Becker y A. Sen. Se le ilustra mediante un estudio del trabajo de un equipo de médicos especialistas en cancerología, que deben elegir una terapéutica para casos complejos. El trabajo muestra que, paralelamente a la toma de decisión sobre cada caso, los médicos reflexionan sobre las buenas prácticas favoreciendo así, por un lado, los saberes de cada uno y del equipo y, por otro lado, la fiabilidad global de las decisiones. El artículo finaliza con una reflexión acerca del concepto de entorno capacitante, del cual se esbozan sus características.

Ce texte présente les objectifs d'une ergonomie constructive, visant non seulement l'efficacité du travail mais le développement constant et conjoint des opérateurs et des organisations. Cette approche articule les modèles socio-économiques proposés par G. Becker et A. Sen. Cette approche est illustrée par une étude du travail d'un collectif de médecins spécialistes en cancérologie devant choisir une thérapeutique pour des cas complexes. On montre que, parallèlement à la prise de décision sur chaque cas, une réflexion sur les bonnes pratiques est menée, favorisant d'une part le développement des savoirs de chacun et du collectif, d'autre part la fiabilité globale des décisions. Le texte se conclut sur la notion d'environnement capacitant, dont les caractéristiques sont esquissées.

The paper presents a constructive view of ergonomics, aiming not only at work efficiency but also at the continuous and joint development of workers and organizations. This approach articulates the socio-economic models proposed by G. Becker and A. Sen. It is illustrated by a study of decisionmaking between specialists in oncology, which have to propose appropriate treatments for complex cases. We show that the role of the team goes beyond decision aid : the discussion on specific cases implies a reflection on the rules themselves. Such a collective reflective activity stimulates the development of both individual and collective knowledge and guarantees the global reliability of the decisions. The conclusion introduces the concept of enabling environment, the characteristics of which are sketched. 
ÍNDICE

Mots-clés: environnement capacitant, ergonomie constructive, activité réflexive, développement des savoirs

Palabras claves: entorno capacitante, ergonomía constructiva, actividad reflexiva, desarrollo de saberes

Keywords: enabling environment, constructive ergonomics, reflective activity, knowledge development

\section{AUTORES}

PIERRE FALZON

Conservatoire national des arts et métiers 41, Rue Gay Lussac 75005 Paris, Franc pierre.falzon@cnam.fr

\section{VANINA MOLLO}

Conservatoire national des arts et métiers 41, Rue Gay Lussac 75005 Paris, France vanina.mollo@cnam.fr 